\title{
Perspectives
}

\section{An Algorithmic Approach to Error Correction: Correcting Three Common Errors at Different Levels}

\author{
Alice Y.W. Chan \\ City University of Hong Kong \\ Becky S.C. Kwan \\ City University of Hong Kong \\ David C.S. Li \\ City University of Hong Kong
}

An algorithmic approach to error correction characterized by four main features: pedagogically sound input requiring minimal cognitive effort, proceduralized steps with instructive examples, explicit rules helping learners conceptualize the correction procedure, and reinforcement exercises, is introduced in this article using three well-defined structural anomalies for exemplification: dangling modifiers, missing relative pronouns and the erroneous there has structure. The remedial instruction materials have been tried out with students at different proficiency levels and feedback was collected through different channels. Comments from both teachers and students indicate that such an approach is effective, versatile and flexible in helping Hong Kong Chinese ESL learners overcome persistent learning errors.

演算式(algorithmic)の誤り訂正には以下の 4 つの型一認知的努力が最小で教育 的効果のあるインプット、わかりやすい例による手順を追ったステップ、学習 者に訂正の過程がわかるような規則の提示、そして練習の強化一があるが、本 稿では、上記の誤り訂正法を 3 つのよく知られた構造的変則例を引きながら説 明する。3つとはぶら下がり (懸垂) 修飾、関係代名詞の欠如、 there has の誤 構文である。異なった能力レベルの学生に対し補修指導材料を使用し、フィー ドバックを様々な方法で収集した。その結果、教師と学生双方から、このよう

JALT Journal, Vol. 24, No. 2, November, 2002 
な方法が、特に香港の中国系ESL学習者の克服しにくいエラー修正に対して効 果があり、多目的に、柔軟性を持って用いることができるとのコメントが寄せ られた。

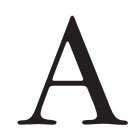

$s$ is well known, error correction is one of the most persistent problems confronted by second and foreign language teachers. Like many of our colleagues, we have frequently been disappointed by the fact that, despite various attempts to make our students aware of recurrent grammatical or structural problems, our students tended to make the same errors again in their language output shortly after corrective feedback was given, suggesting that students failed to internalize the correct model. A substantial body of research in Second Language Acquisition (SLA) has shown that learners may or may not notice the errors that they have made (cf. the noticing hypothesis, Schmidt, 1990, 1992), and even if a particular anomalous form has been noticed, the grammatical rule in question is often too abstract and complex to be mastered upon the teacher's corrective feedback. One possible reason is that the learner may have reached a plateau in the L2 learning process suggesting that fossilization has taken place. There may be other relevant factors, such as the degree of complexity of the grammatical phenomenon or phenomena in question, and whether the teacher is able to use relatively jargon-free metalanguage to make explicit fine structural nuances.

Advocates of the hard-core version of the communicative approach to language teaching tend to dismiss error correction for two main reasons: (a) the belief that all attempts to draw learners' attention to formal anomalies would discourage the learner from producing output in L2, which in turn would inhibit acquisition; and (b) the claim that there is no interface between learning (which takes place consciously with explicit instruction) and acquisition (which takes place subconsciously, typically through mere exposure to the target language in natural, meaning-oriented settings) (Krashen, 1981, 1982, 1985). However, a substantial body of recent research in SLA has shown that focus on form in context (Long, 1991; Long \& Robinson, 1998) or form-focused instruction in general (Spada, 1997) has great potential for enhancing the learners' language accuracy in their L2 output, thereby accelerating the rate of SLA.

In an attempt to improve the quality of our own remedial instruction, we experimented with an approach partly inspired by theoretical and 
empirical studies in consciousness-raising research (Sharwood Smith, 1981; Rutherford, 1987, 1988; Schmidt, 1990); and partly by more recent research on form-focused instruction and explicit corrective feedback (e.g. Doughty \& Williams, 1998; Granger \& Tribble, 1998), with an aim to explore the pedagogical potential of explicit, form-focused, corrective feedback in the Hong Kong ESL classroom. In our design of remedial instruction materials, we tried to analyze the learning task from the learner's perspective in order to make the remedial input cognitively accessible to even the weakest learners by minimizing the cognitive effort required to proceed from one proceduralized step to the next. We call such an approach an algorithmic approach to error correction (cf. Sharwood Smith, 1981), in the sense that there is a set of rules or procedures that students follow in order to overcome the lexico-grammatical problem in question. In more specific terms, the teaching approach that we have adopted in our materials is characterized by four main features (see Chan \& Li, 2002; Li \& Chan, 2000, 2001): (a) pedagogically sound input requiring minimal cognitive effort; (b) proceduralized steps supported by instructive examples; (c) explicit rules to help learners conceptualize the correction procedure; and (d) reinforcement exercises.

Such an algorithmic approach to error correction is versatile and flexible in that it can be used for error types of different complexity levels catering to learners at various proficiency levels. The remedial materials thus designed can be used either by teachers in the classroom with or without adaptation depending on the needs of their students, or for selflearning purposes by learners themselves. For this approach to work satisfactorily, however, one prerequisite is that the error type in question must lend itself to effective remedial instruction through a sequence of proceduralized steps. In this article, we will exemplify the algorithmic approach using the materials we designed for three error types at different complexity levels: dangling modifiers, missing relative pronouns, and erroneous there has structures. For ease of illustration, the correction procedure will be structured in different phases, with each phase focusing on one specific teaching goal and indicating what the teacher should or may do to help students overcome the error and progressively approximate the target structure.

Advanced Level: Dangling Modifiers 


\section{Nature and Causes of Problem}

Many advanced ESL learners have problems writing complex sentences involving a non-finite clause with no overt subject. The problem of dangling modifiers often results, as in the following two examples:

1.* $\quad$ Entering the stadium, the size of the crowd surprised John.

2.* Having eaten our lunch, the ship departed.

The core of the problem lies in the fact that the subject of the main clause cannot be interpreted as the subject of the subordinate clause/ non-finite clause. Inadequate knowledge of the correct usage of the target structure is probably the only cause of this problem. Students are unaware that the subject of the main clause (e.g., 'the size of the crowd' in sentence 1, or 'the ship' in sentence 2) has to be the same as the implicit subject of the subordinate clause/non-finite clause (e.g., "entering the stadium" in sentence 1, and "having eaten our lunch" in sentence 2).

\section{Correcting the Problem}

Phase One: Illustrate The Correct Use of the Structure with Correct Examples

1. Look at the following sentences:

(i) Entering the room, we turned on the light.

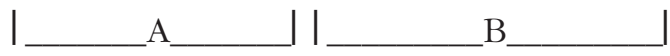

(ii) Walking along the streets, John met Mary.

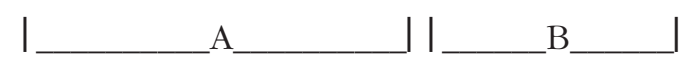

2. What is the subject of B in sentence (i)? Circle it.

3. Is there a subject in $\mathrm{A}$ ?

4 But do we know who entered the room? Who?

5. Compare the persons who entered the room and the subject of B. What do you notice? Are they the same persons or different persons?

6. Look at sentence (ii) now. What is the subject of B? Circle it. 
7. Who walked along the streets?

8. Again, compare the person who walked along the streets with the subject of B. Are they the same?

Phase Two: Introduce the Rule

9. In a complex sentence with two clauses, if the first clause (A) does not have a subject, the subject of the second clause (B) will be interpreted as its subject.

Missing Subject of A (subordinate clause) = Subject of B (main clause)

Phase Three: Help Students Notice the Core of the Error

10. Now let us look at sentence (iii) below. It has a similar structure to sentences (i) and (ii).

(iii) Entering the stadium, the size of the crowd surprised John.

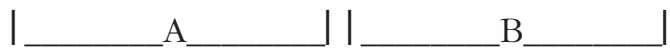

11. What is the subject of $\mathrm{B}$ ?

12. Can the size of the crowd be used as the subject of $\mathrm{A}$ ?

Phase Four: Highlight the Nature of the Problem

13. Sentence (iii) is wrong because the missing subject of A $\neq$ the subject of $\mathrm{B}$.

Phase Five: Help Students Correct The Sentence by Supplying the Appropriate Subject

14. So who entered the stadium?

15. Look at the rule in step 9 above.

What should be the subject of the second clause?

16. Rewrite B by changing the subject to John.

(iv) Entering the stadium, John

Phase Six: Reinforce the Correct Usage by Using Other Examples 
Phase Seven: Reinforcement Exercises

\section{Intermediate Level: Missing Relative Pronouns in Relative Clauses}

\section{Nature and Causes of Problem}

Another common error associated with the formation of complex sentences that ESL learners often make is the omission of a suitable relative pronoun in a relative clause as in the following two examples:

3.* I remembered the accident happened yesterday.

4.* There were altogether ten parents participated in the interview.

This error can be attributed to mother-tongue influence. In Chinese/ Cantonese, the mother tongue of most of the students in Hong Kong, there is no distinction between finite and non-finite verbs, and serial verb constructions with more than one verb/verb phrase juxtaposed in the same construction without having any markers to show the relationship between them are perfectly acceptable and very common. What complicates the situation is that the Chinese/Cantonese sentences corresponding to sentences 3 and 4 do not require a relative clause structure or a relative pronoun (see sentences 5 and 6 below). It is thus not surprising for Chinese ESL learners to write English sentences with a chain of finite verbs. Here are two examples:

5. ngo5 gei3 dak1 ji3 ngoi6 si6 zok3 tin1 faat3 sang1 dik $1^{1}$

I remember accident is yesterday happen PRT ${ }^{2}$

6. zung2 gung6 jau5 sap6 ming4 gaa1 zoeng2 zip3 sau6 fong2 man6

total has ten $\mathrm{CL}^{3}$ parents receive interview

Apart from L1-related factors, the allowance of a seemingly similar structure in English also contributes to L2 learners' misunderstanding of the correct usage. Sentences such as 7 and 8 below, containing a reduced relative clause with the relative pronoun and the finite verb omitted, may cause confusion. Learners who are unaware of the differences between the acceptable reduced relative structure and the erroneous sentences 
may incorrectly apply the rule of omission of relative pronouns. Here are two example sentences:

7. I like her book published last year.

8. I have seen some of the parents interviewed.

\section{Correcting the Problem}

Phase One: Help Students Notice the Error

1. Are the following sentences correct?

Make a "口"if you think so, and a "口" if you don't think so.

(i) Mary likes John's book published last year.

(ii) I met two parents attended the interview yesterday.

(iii) I remember the accident happened yesterday.

(iv) We note from the reports appeared at the front page of the SCMP.

(v) There were altogether twenty students took the test.

Phase Two: Explain the Acceptability of the Grammatical Sentences by Highlighting the Voice of the Verb Concerned (Whether it is in Active or Passive Voice)

2. Compare sentences (i) and (ii).

(i) 4 Mary likes John's book published last year.

(ii) I I met two parents attended the interview yesterday.

3. Look at sentence (i). What does Mary like?

4. What happened to John's book last year?

5. Note the correct pattern.

uJohn's book published last year.

uJohn's book was published last year.

6. Rewrite sentence (i) into two simple sentences, A and B. B 
7. Circle the noun phrase which is found in both A and B.

8. Since John's book is found in both A and B, we can turn $\mathrm{B}$ into a relative clause. Which relative pronoun (e.g., which, who, whom, whose, that) can we use?

9. Combine $\mathrm{A}$ and $\mathrm{B}$ using the relative pronoun suggested.

10. Observe: Is the verb published in the active or passive voice?

11. What is the form of the verb published? Is it a present tense verb, a past tense verb, a present participle, or a past participle?

Phase Three: Make Explicit the Context Where Relative Pronouns Can Be Omitted

12. Since published is a participle, the subject relative pronoun and the verb to be can be deleted. Here is an example:

(vi) [ [ I like her book ] [which was published last year.]

A

B

In a complex sentence $\quad[\ldots$ VERB $\ldots$ VERB ... $]$

A B

If $\quad \mathrm{B}$ is a relative clause and the VERB in $\mathrm{B}=$ PARTICIPLE

Then Subject relative pronoun and VERB TO BE can be deleted

Phase Four: Explain the Unacceptability of the Ungrammatical Sentences

13. Now, look again at sentence (ii). Who did I meet yesterday?

14. What did the two parents do?

15. Which is correct?

Two parents attended the interview; or

Two parents were attended the interview. 
16. Rewrite sentence (ii) to form two simple sentences, $\mathrm{A}$ and $\mathrm{B}$.

A

17. Circle the noun phrase that is found in both A and B.

18. Replace the noun phrase in B by a suitable relative pronoun. (e.g., who, which, etc.)

19. Combine A and B using the relative pronoun suggested.

20. Observe: Is the verb attended in the active or passive voice?

21. What is the form of the verb attended? Is it a present tense verb, a past tense verb, a present participle, or a past participle?

Phase Five: Spell Out the Context Where a Relative Pronoun Must Be Used

22. Since attended is not a participle, the subject relative pronoun cannot be deleted.

In a sentence $\quad[\ldots$ VERB ... VERB ...]

A B

If $\quad B$ is a relative clause and Verb in $\mathrm{B} \neq$ PARTICIPLE

Then a relative pronoun must be used

(vii) 0 [ I met two parents ] [ who attended the interview yesterday ].

(viii) 0 [ I met two parents ] [ attended the interview yesterday ].

Phase Six: Introduce Alternative Ways of Combining Clauses

23. Following the first rule in step 12, we can rewrite sentence (viii) by changing the verb in B to an -ing participle. The subject relative pronoun can be deleted.

Here is an example:

(ix) 0 [ I met two parents ] [ attending the interview yesterday ]. 
Phase Seven: Reinforcement Exercises

Elementary Level: the Erroneous 'There has' Structure

Nature and Causes of Problem

As far as elementary ESL students in Hong Kong are concerned, the mistaken construction of the 'there be' structure is one of the most common problems that occurs. The verb HAVE is often misused in place of the verb to $\mathrm{BE}$ to express the existential or presentative function, as in the following:

9.* There has a book on the table.

10.* There have many computers in the room.

The probable causes of this structural problem are both L1 and L2 related. First, the corresponding existential meaning in Chinese/Cantonese is expressed using jau 5 'have', rather than the verb to BE as used in English. Here is an example:

11. maa5 lou6 soeng6 jau5 han2 do1 ce1 road above has many cars

Second, the dummy subject 'there' in a 'there BE' sentence is often mistakenly regarded as syntactically and semantically equivalent to the Cantonese sentence-initial adverb go 2 dou 6 '(the demonstrative) there' (as in example 12). This, coupled with the misuse of 'have' to mean the existential yau 5 in Chinese, results in the erroneous 'there has/have' structure as in sentences 9 and 10 .

12. go2 dou6 jau5 hou 2 do1 jan 4

there has many people

Negative transfer from L1 is not necessarily the only reason that may account for students' problems with the structure. Students' inadequate mastery of the different forms of the verb to $\mathrm{BE}$ in the target language may also contribute to the error. As the perfect forms 'have been' and 'has been' of the verb to BE are morphologically similar to the verb HAVE, probable confusion due to such acceptable structures as sentences 13 and 14 may also lead to the anomaly.

13. There have been a lot of visitors in Hong Kong.

14. There has been a dog sleeping there. 
Correcting the Problem

Phase One: Alert Students to the Constituents of the Target Structure

1. (T shows a picture.) Look at the picture. What is on the tree?

(i) A bird is on the tree.

2. Sentence (i) tells us that [ something ] IS/ARE

[ somewhere]. But to say that [something] IS/ARE

[ somewhere ], you can also say There BE [ something ]

[ somewhere].

[ something ] IS/ARE [ somewhere ]

There BE [ something ] [somewhere ]

3. What is something in sentence (i)?

4. What is somewhere in sentence (i)?

5. Now, rewrite sentence (i) using the There BE structure shown above.

Phase Two: Consolidate Students' Understanding by Comparing the Target Structure with a Familiar Structure

6. Now compare sentence (i) with the rewritten sentence.

(ii) There BE

a bird

on the tree.

(i)

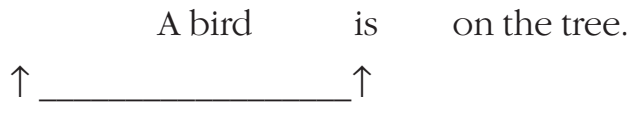

7. We can't use $B E$ as the verb of the sentence. Cross out $B E$ and move the verb is to the position after There.

8. Now, can you answer the question again: What is on the tree?

Phase Three: Reinforce Students' Understanding by Using Other Examples

9. Let us look at another picture (two pictures hanging on the wall): What are on the wall? 
(iii) are

$$
\text { something somewhere }
$$

10. What is something in sentence (iii)?

11. What is somewhere in sentence (iii)?

12. Following the rule in step 2 above, rewrite sentence (iii).

13. Again compare sentence (iii) with the rewritten sentence.

(iv) There BE two pictures on the wall.

Two pictures are on the wall.

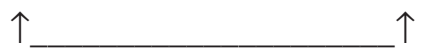

14. We can't use $B E$ as the verb of the sentence. Cross out $B E$ and move the verb are to the position after There.

15. Now can you answer the question again: What are on the wall?

Phase Four: Help Students Notice the Nature of the Erroneous Structure

16. Now look at the following sentence. What's wrong with it?

(v) $\times$ There has a book on the table.

17. What is something in sentence (v)?

18. What is somewhere in sentence (v)?

19. Can we say $A$ book has on the table?

Phase Five: Highlight the Nature of the Problem

20. Since we can't say A book has on the table, we can't say There has a book on the table.

[ [ something] has [ somewhere] $\mathrm{C}$

口 There HAS [ something ][somewhere ]

Phase Six: Reinforcement Exercises with and without Contrastive Examples 
Dangling modifiers, missing relative pronouns and erroneous therehas structures, are all morpho-syntactically well-defined error types, which lend themselves very well to error correction through the algorithmic approach. These three sets of materials, together with those designed for ten other error types such as resumptive pronouns and faulty parallelism, have been tried out in an ongoing research project, which involves six secondary and tertiary teachers who used the materials in class with their students (over 200 in total), as well as a number of tertiary students ( 21 in total), who used the materials in a self-learning mode. Feedback on the materials was collected through focus-group meetings with teachers, post-teaching protocols filled out by participating teachers, and self-access evaluation forms filled out by students. In this section, we will briefly examine their responses.

The participating teachers found the materials effective, in that their students became better aware of the problems in the erroneous structures and hence were able to correct them. They also reported that their use of the taught items improved, and the materials helped them gain concrete grammar knowledge. Comments given in the self-access evaluation forms filled out by the students who used the materials in a self-learning mode, also reflected that the materials helped them see the gist of the problems in the erroneous structures as they corrected the errors.

Responses to the user-friendliness features of the materials were on the whole positive. The teachers found the proceduralized correction steps and the rules provided in the materials straightforward and clear enough to help students see and rectify the erroneous structures. The students were also able to follow the materials with little difficulty.

Most of the students who used the materials in a self-learning mode commented on the self-evaluation forms that the materials were clearly written and easy to follow, with the majority of them being able to finish the steps within 30 minutes.

\section{Conclusion and Adaptation}

In this article, we have demonstrated how an algorithmic approach to error correction can help learners at different proficiency levels overcome persistent, common English errors. Our experience suggests that, by virtue of the design features of the materials, the more structured the individual steps, the more likely that the approach will work. For more complex errors such as the dangling modifier problem, some use of grammatical jargon (e.g., main clause, subordinate clause) is inevitable if students are to master the subtle differences between the normative 
structures and the anomalies; yet for less sophisticated problems, technical terms should better be avoided. The algorithmic approach to error correction suggested here has received some empirical support, showing that it is effective, versatile and flexible with Hong Kong Chinese learners (Chan \& Li, 2002; Li \& Chan, 2000, 2001). It is our belief that properly administered, this approach will also work well with learners from other L1 backgrounds.

As might have been observed, some of the steps in the materials exemplified may appear to be rather redundant and repetitive. However, we need to emphasize that the repetitiveness is intended as part of the consciousness-raising approach we adopted. Since the materials target relatively weak students, extra guidance realized in explicitness and repetition is necessary to help students with the (re-)discovery of the rules. It is through explicitness that we raise students' consciousness of the tacit rules and through repetitions that we reinforce this consciousness. Having said this, we do not mean that repetitions are necessary all the time, nor do we imply that teachers need to follow every single step before students can arrive at satisfactory learning of the items. Rather, teachers are encouraged to adjust the steps based on their own knowledge of their students' proficiency and ability. At junctions where students' responses deviate from the expected "answers" to the leading questions, adaptations such as reformulating and re-ordering of the questions/steps are particularly essential.

The techniques suggested in this article, though pedagogically sound, are not meant to be exhaustive. They may not be useful for all sentences related to the error type in question and may have some lexical, contextual or structural constraints. Take the missing relative pronoun problem as an example. The technique proposed may not work well with all types of nouns and all types of verbs. Sentences with inanimate nouns such as * I found two books fell on the floor may not be corrected as easily as sentences with animate nouns such as the ones used in the remedial instruction materials (e.g., "I met two parents attended the interview yesterday). Another constraint is that since the materials were designed primarily to help students notice the correct use of sentences which contain a noun phrase with a relative clause as its post-modifier (either finite with an overt relative pronoun, or non-finite with no relative pronoun) (e.g., I met two parents who attended the interview yesterday / I met two parents attending the interview yesterday). Sentences whose surface structures bear resemblance to the erroneous structure but which do not contain such post-modification (e.g., I remembered you beat 
me yesterday) do not fit the evaluation metric suggested and hence are not targeted here. The subtlety of the varying degree of acceptability of sentences with unattached clauses is also an issue not addressed in our materials. Though sentences with dangling modifiers such as 1 and 2 are regarded as anomalous, other similar ones like To apply for the post, an application form must be submitted are less objectionable and may be acceptable to many native speakers of English. As the principal aim of our remedial instruction materials is to help students identify the nature of the anomalies and formulate a rule which governs the proper use of the structures, whether and when these subtleties should be brought to discussion is left to the discretion of the teacher. It is suggested that teachers take any form of adaptation needed to prevent learners from drawing erroneous conclusions.

\section{Acknowledgments}

The remedial instruction material described in this article was designed for a CityU strategic research project (grant no: 7000998). The support of the City University of Hong Kong Research Committee is acknowledged. We would also like to thank Ms. Emily Law for her administrative support, and the six participating teachers of the project for their cooperation and feedback.

Alice Y.W. Chan, Becky S. C. Kwan and David C.S. Li teach at the Department of English and Communication, City University of Hong Kong. Alice Chan's research interests include phonetics and phonology, contrastive analysis, syntax, lexicography and error correction. Becky Kwan's research interests include genre analysis, English for academic purposes and English for specific purposes. David C. S. Li's research interests include cross-linguistic influence, code-switching, World Englishes and intercultural communication.

\section{Notes}

1. Numbers represent tones (phonemic in Cantonese).

2. PRT is the abbreviation for Chinese sentence particles.

3. $\mathrm{CL}$ is the abbreviation for Chinese Classifiers such as ming 4, go3.

\section{References}

Chan, A.Y.W., \& Li, D.C.S. (2002). Form-focused remedial instruction: An empirical study. International Journal of Applied Linguistics, 12(1), 24-53.

Doughty, C., \& Williams, J. (Eds.). (1998). Focus on form in classroom second 
language acquisition. Cambridge: Cambridge University Press.

Granger, S., \& Tribble, C. (1998). Learner corpus data in the foreign language classroom: Form-focused instruction and data-driven learning. In S. Granger (Ed.), Learner English on computer (pp. 199-209). London: Longman.

Krashen, S. (1981). Second language acquisition and second language learning. Oxford: Pergamon Press.

Krashen, S. (1982). Principles and practice in second language acquisition. Oxford: Pergamon Press.

Krashen, S. (1985). The input hypothesis: Issues and implications. London: Longman.

Li, D.C.S., \& Chan, A.Y.W. (2000). Form-focused negative feedback: Toward a pedagogically sound model of remedial instruction. In D. C.S. Li, A. Lin \& W.K. Tsang (Eds.), Language and education in postcolonial Hong Kong (pp. 333-351). Hong Kong: Linguistic Society of Hong Kong.

Li, D.C.S., \& Chan, A.Y.W. (2001). Form-focused negative feedback: Correcting three common errors. TESL Reporter, 34(1), 22-34.

Long, M. (1991). Focus on form: A design feature in language teaching methodology. In K. de Bot, R. Ginsberg \& C. Kramsch (Eds.), Foreign language research in cross-cultural perspective (pp. 39-52). Amsterdam: John Benjamins.

Long, M. \& Robinson, P. (1998). Focus on form: theory, research, and practice. In C. Doughty \& J. Williams (Eds.), Focus on form in classroom second language acquisition (pp.15-41). Cambridge: Cambridge University Press.

Rutherford, W. (1987). Second language grammar: Learning and teaching. New York: Longman.

Rutherford, W. (1988). Consciousness raising and universal grammar. In W. Rutherford \& M. Sharwood Smith (Eds.), Grammar and second language teaching: A book of readings (pp.107-116). New York: Newbury House.

Schmidt, R. (1990). The role of consciousness in second language learning. Applied Linguistics, 11, 129-158.

Schmidt, R. (1992). Psychological mechanisms underlying second language fluency. Studies in Second Language Acquisition, 14, 357-385.

Sharwood Smith, M. (1981). Consciousness-raising and the second language learner. Applied Linguistics, 2, 159-169.

Spada, N. (1997). Form-focused instruction and second language acquisition: A review of classroom and laboratory research. Language Teaching, 30, 7387.

(Received January 13, 2002; Revised April 18, 2002) 